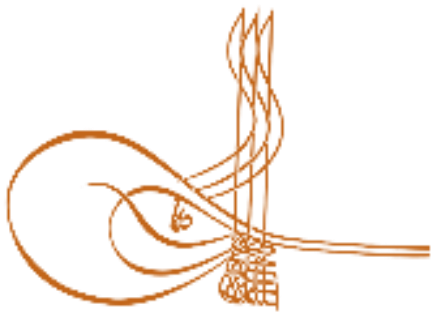

www.turkishstudies.net/social
Turkish Studies - Social Sciences

eISSN: $2667-5617$

Research Article / Araștırma Makalesi

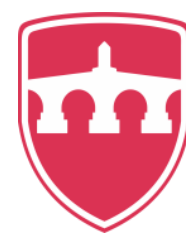

INTERNATIONAL

BALKAN

UNIVERSITY

Sponsored by IBU

\title{
İş Sağlığı ve Güvenliği Uygulamaları ve İş Disiplininin Çalışan Performansı Üzerindeki Etkisi: Erzurum Örneği*
}

The Effect of Occupational Health and Safety and Work Discipline on Employee Performance: The Case of Erzurum the Effect of Occupational Health and Safety And work Discipline on Employee Performance: The Case of Erzurum

\author{
Sefa Çelik ${ }^{* *}-$ Dilşad Güzel $^{* * *}$
}

\begin{abstract}
Occupational health and safety (OHS) is a concept that has been understood especially in recent years. Occupational health and safety can be defined as practices aimed at protecting the health and safety of employees in a workplace, eliminating or minimizing accidents or occupational diseases that may occur in the workplace. Work discipline is the name given to all sanctions that prevent employees from deviating from the company's longterm and short-term goals within the framework of a set of rules. The purpose of this study is to investigate the relationship between occupational health and safety and work discipline on employee performance. In this context, the occupational health and safety practises, history of occupational health and safety and legal requirements are explained in first part. In the second part work discipline in the work environment is explained by giving legal procedures. Finally, the concept of performance and business performance are given and theoretical part of the research has been completed. In the application part of the study, face to face questionnaire was applied to the employees of different companies that operating in the good and service sector in Erzurum. The effect of occupational health and safety practises and work discipline on employee performance is explained theoretically. The hypothesis and the model of the survey were tested with multiple linear regressions. As a result, it was observed that occupational health and safety practises and work discipline have an impact on employee performance.
\end{abstract}

\footnotetext{
* Bu çalışma, Atatürk Üniversitesi Sosyal Bilimler Enstitüsü tarafından 2018'de kabul edilen "İş Sağllğ ve Güvenliği Uygulamaları ve İş Disiplininin Çalışan Performansı Üzerindeki Etkisi: Erzurum Örneği” isimli yüksek lisans tezinden faydalanılarak oluşturulmuştur.

** Arş. Gör. Atatürk Üniversitesi, İktisadi ve İdari Bilimler Fakültesi, İşletme Bölümü Res. Asst. Atatürk University, Faculty of Economics and Administrative Sciences, Department of Business ORCID 0000-0003-3151-1324

sefa.celik@atauni.edu.tr

*** Doç.Dr. Atatürk Üniversitesi, İktisadi ve İdari Bilimler Fakültesi, İşletme Bölümü

Assoc. Prof. Dr. Atatürk University, Faculty of Economics and Administrative Sciences, Department of Business ORCID 0000-0003-1421-7692

dguzel@atauni.edu.tr

Cite as/ Atıf: Çelik, S., Güzel, D. (2020). İş sağlığı ve güvenliği uygulamaları ve iş disiplininin çalışan performans1 üzerindeki etkisi: erzurum örneği, Turkish Studies - Social, 15(1), 169-186. https://dx.doi.org/10.29228/TurkishStudies.32645

Received/Geliş: 23 August/Ağustos 2019

Accepted/Kabul: 25 February/Şubat 2020

Copyright (C) INTAC LTD, Turkey

Checked by plagiarism software Published/Yayın: 29 February/Şubat 2020 CC BY-NC 4.0
} 
Structured Abstract: The World Health Organization (WHO) has defined the concept of health as being in complete harmony not only physically but also mentally and socially.

Occupational health, which has become a popular concept today, has not meant much for employers or society in the past centuries. Because there were people employed by slaves or criminals who could not get a place in the society for dangerous works. So working under such difficult conditions meant punishing them. For people working under these circumstances, injury or death were commonplace. The fact that such employees have health problems or dies has not seen the reaction required by the society because of the understanding of punishment system. This social problem has been the basis of the fact that the concept of occupational health has not been considered and developed for many years.

The concept of occupational safety is methodical studies performed to protect the employees from the hazards that may occur during the execution of the work and the conditions that may harm health (Yiğit, 2011: 4).

The concept of Occupational Health and Safety is a new concept formed by the combination of two different terms. But the first part of these two concepts is examined by medical sciences and the other part is examined by technical sciences. The health science part of the job is that employees lose their health because of their working environment. The part that concerns technical sciences is that employees are exposed to fatal accidents due to insufficient measures (Kılıç, 2006: 18).

The productivity of employees who spend most of their time in the workplace depends on the work environment. Employee productivity and health are influenced by internal and external influences as well as personal trends (Sekulová \& Šimon, 2010: 462). While the personnel working in peaceful, safe and happy workplaces provide efficiency in all areas, it is not possible in the opposite situations. Therefore, the importance of OHS has increased rapidly both in the workplaces and in the law. A work accident or occupational disease affects the worker and the family of the worker. This indirectly affects the society and the economy of the country within the scope of the right to social security under the leadership of issues such as dislike of working conditions and workers' rights. So, the physical and mental health of the worker can affect the whole society.

As the existing features of an organization affect employee satisfaction and therefore quality, there is a need to place employee relations according to a certain order and procedure. There are many factors that affect this system while creating an effective working relations system and the effect levels of these factors are different from each other (Uyargil et al., 2009: 17).

The concept of performance is one of the important issues that a business should focus on. The company should not fall below the specified standards in order to realize its objectives, to obtain high rates of profit, to maintain its profitability and to maintain its strength in the competitive environment. For this, it should give the necessary importance to the concept of performance measured by efficiency.

The aim of the study is to determine the effect of Occupational Health and Safety practices and work discipline practices, which are applied in the workplaces and required by law, on employee performance. Another aim of the research; To contribute to the domestic literature on Occupational Health ande Safety practices.

The most important benefit expected from the research is to obtain information about the performance of company employees and to identify the missing or insufficient parts in terms of Occupational Health ande Safety and work discipline criteria and to contribute to the elimination of these deficiencies or inadequacies. In this respect, improving the performance of employees is another benefit expected from the research. The final benefit expected from the research is to encourage further research in this field by attracting the interest of firms, academicians and related institutions and organizations, thus leading the gap in the domestic literature.

The aim of this study was to determine the effect of occupational health and safety practices and discipline practices on employee performance in Erzurum province. The following results were obtained by analyzing the collected information.

It is understood that the service sector needs more qualified personnel in terms of education level. In terms of the year worked, it was concluded that the production sector could continue with its existing employees for a long time, but the circulation of employees in the service sector was rapid.

In the variables related to occupational health and safety, it was found that the average of the good sector (4.24) had a higher average than the service sector average (3.95). Although the education level of the occupational health and safety sector is lower, it is determined that they have more information about this subject. It can be said 
that the good sector performs more risky works than the service sector and works with these risks continuously increases the awareness and awareness in this field.

While the goods sector exceeded the average in terms of the compliance of working hours with the health conditions of the employee, the service sector remained far behind. It has been concluded that tolerance is possible in terms of working time in the good sector, but for service sector is more rigid in this regard.

It has been determined that the procedures applied in business discipline do not create an enjoyable working environment in both sectors. It is understood that the procedures applied in the sectors are not compulsory by the employees but are enforced. It was concluded that the good sector was more successful than the service sector and that the system was accepted and settled by the employees.

As a result of the analysis of the relationships between the variables in the research model, it was determined that occupational health and safety practices and work discipline practices had a positive and statistically significant effect on employee performance. These results support the research model.

In order to determine whether occupational health and safety practices, job discipline and employee performance variables differ between sectors, it can be seen these variables differ between sectors. Accordingly, these variables were found to be higher in the goods sector than the services sector.

Keywords: Occupational Health, Occupational Safety, Work Discipline, Performance

Öz: İş Sağlığı ve Güvenliği (İSG) özellikle son yıllarda önemi anlaşılmış olan bir kavram olarak karşımıza çıkmaktadır. İş Sağlığı ve Güvenliği, bir işyerinde çalışanların sağlık ve güvenliklerini korumayı, işyerinde meydana gelmesi muhtemel kaza veya meslek hastalıklarını yok etmeyi veya minimum miktara indirmeyi amaçlayan uygulamalar olarak tanımlanabilir. İş Disiplini ise, çalışanların birtakım kurallar çerçevesinde firmanın uzun dönem ve kısa dönem hedeflerinden sapmalarının önüne geçen tüm yaptırımlara verilen isimdir. $\mathrm{Bu}$ çalışmanın amacı, İş Sağlığı ve Güvenliği uygulamaları ile İş Disiplini uygulamalarının Çalışan Performansı üzerindeki etkisinin incelenmesidir. Bu bağlamda çalışmanın birinci bölümünde İş Sağlığı ve Güvenliği uygulamalarının neler olduğu açıklanmış, İş Sağlığı ve Güvenliğinin tarihi gelişimi incelenmiş ve bu alandaki yasal zorunluluklar belirtilmiştir. Çalışmanın ikinci bölümünde işyeri ortamında İş Disiplini kavramı açıklanmış, İş Disiplininin neden önemli olduğu konusunda bilgi verilmiş, performans ve Çalışan Performansı kavramları hakkında detaylı bilgi verilerek araştırmanın teorik bölümü tamamlanmıştır. Çalışmanın, uygulama kısmında Erzurum ilinde mamul sektörü ve hizmet sektöründe faaliyet gösteren farklı firmaların çalışanlarına yüz yüze görüşme yöntemi ile anket uygulanmıştır. İş Sağlığı ve Güvenliği uygulamaları ile İş Disiplininin çalışan performansına etkisi teorik olarak açıklanmıştır. Bu doğrultuda geliştirilen hipotezler ve araştırma modeli, çoklu regresyon analizi aracılığı ile test edilmiştir. Sonuç olarak; İş Sağlığı ve Güvenliği uygulamaları ile İş Disiplini uygulamalarının Çalışan Performansı üzerinde etkili olduğu tespit edilmiştir.

Anahtar Kelimeler: İş Sağlı̆̆ı, İş Güvenliği, İş Disiplini, Performans

\section{Giriş}

Sanayileşme süreci insanlığa fazlasıyla zaman ve para kazandırmış fakat birçok problemi de beraberinde getirmiştir. Bu süreçten sonra gün geçtikçe artan iş kazaları ve meslek hastalıkları çalışma ortamında birtakım düzenlemeler yapılması gerekliliğini doğurmuştur. Çünkü insanlar hayatlarını sürdürebilmek için çalışmak zorundadırlar ve zamanlarının büyük bir bölümünü çalıştıkları işyerlerinde geçirmektedirler. Dolayısıyla çalışma ortamında yer alan birçok etken çalışanın performansını ve en önemlisi sağlığını tehdit edebilmektedir. Çalışanın fiziksel veya ruhsal sağlığını etkileyebilecek bir iş kazası veya meslek hastalığı o kişinin işgücü ve işgünü kayıplarına neden olabilmektedir. Bu durumdan çalışanın kendisi, işvereni, ailesi ve dolaylı olarak ülke ekonomisi olumsuz etkilenebilmektedir.

İş Sağlığı ve Güvenliğinin temel amacı, çalışanların çalıştıkları ortam ile fiziksel ve ruhsal olarak tam bir uyum içinde olmalarını sağlamaktır. Çünkü çalışanın çalıştı̆̆ı ortamda kendini güvende ve mutlu hissetmesi performans açısından büyük önem taşımaktadır. İş Sağlığı ve Güvenliği noktasında 
dünyada çok yol kat edilmemiş olsa bile yapılan çalışmalarla konunun önemi anlaşılmaya başlanmıştır. Ülkelerin bu noktada uyguladıkları yasal düzenlemeler artan bir şekilde karşımıza çıkmaktadır.

Araştırmanın amacı, İş Sağlığı ve Güvenliği uygulamaları ile İş Disiplini uygulamalarının Çalışan Performansı üzerindeki etkisini irdeleyerek sonuçların ilgili işletmelere Çalışan Performansını artırmada katkıda bulunmasını sağlamaktır.

\section{1. İş Sağlı̆̆ı}

İş Sağlığı kavramına geçmeden önce sağlık kavramının tanımlanması yerinde olacaktır. Dünya Sağlık Örgütü (WHO) sağlık kavramını, bir insanın yalnızca fiziki olarak değil, aynı zamanda ruhsal ve sosyal yönden de tam bir uyum hali içinde olması şeklinde tanımlamıştır (Robinson \& Elkan, 1996).

Başka bir tanımda ise İş Sağlığı, çalışılan ortam ve bu ortamda kullanılan malzemelerden doğabilecek tehlikeleri minimum düzeye indirmeye ya da ortadan kaldırmaya çalışan çabalar bütünü olarak tanımlanmıştır (Demircioğlu ve Centel, 2003: 154).

İş Sağlığı ve Güvenliği uygulamalarının eksiksiz ve kusursuz uygulandığı ve kazaların minimum düzeye indirilmeye çalışıldığ 1 bir ortam, çalışan kişinin fiziksel ve ruhsal performansını iyileştirerek çalışanın sağlığını koruduğu için; iş kazası veya meslek hastalığı yaşanması riskinin önüne geçilecektir. Bunun için sağlı̆ğ tehlikeye düşürebilecek durumların net analizinin belirli periyotlarla ve aksatılmadan yapılması gerekmektedir (Turan, 2016: 14).

\section{2. İş Güvenliği}

Güvenlik kavramı en genel anlamıyla emniyet içinde olma duygusu olarak tanımlanabilir (Karadoğan, 2014: 21). İş Güvenliği kavramı ise: işyerlerinde işin yürütülmesi sırasında meydana gelebilecek tehlikelerden ve sağlığa zarar verebilecek koşullardan korunmak için yapılan metotlu çalışmalardır (Yiğit, 2011: 4).

Güvenlik, sadece mikroekonomi açısından değil ayrıca makroekonomi açısından da büyük önem taşımaktadır. Çin'de yapılan bir araştırmada 1979-2008 yılları arasındaki veriler analiz edildiğinde İş Güvenliği ile ülkenin makroekonomik gelişimi arasında bir bağlantı olduğu tespit edilmiştir. Ülke ekonomisi büyüme yaşadığı zamanlarda iş kazaları artmakta, küçülme yaşandığ zamanlarda ise iş kazaları azalmaktadır (Li, Xueqiu \& Li, 2011: 82). Dolayısıyla ekonomisi büyüme evresinde olan ülkelerin İş Güvenliği konusunda daha hassas olmaları gerekmektedir (Akpınar, 2014: $41)$.

\section{3. İş Sağlı̆̆ı ve Güvenliği}

İş Sağlığı ve Güvenliği, çalışma hayatındaki olumsuz durumların çalışan sağlığına herhangi bir zarar vermemesi adına yapılan çalışmalardır (Karadoğan, 2014: 21). İş Sağlığı ve Güvenliği işin yapıldığ 1 süre içerisinde işyerindeki fiziki nedenlerden kaynaklanan ve işçilerin maruz kaldıkları olumsuz etkenlerin azaltılması veya ortadan kaldırılması olarak tanımlanmıştır (Balkır, 2012: 2).

İSG kavramı iki farklı terimin bir araya gelmesiyle oluşmuş yeni bir kavramdır. Fakat bu iki kavramın ilk bölümünü tıbbi bilimler incelerken diğer kısmı teknik bilimler tarafından incelenmektedir. İşin sağ lık bilimini ilgilendiren kısmı çalışanların çalışma ortamları nedeniyle sağlıklarını kaybetmeleri; teknik bilimleri ilgilendiren kısmı ise yetersiz önlemler sebebiyle çalışanların ölümcül sonuçlar doğuran kazalara maruz kalmalarıdır (Kılıç, 2006: 18).

İş Sağlığı ve Güvenliğinin amaçları şöyle sıralanmıştır (Turan, 2016: 14);

- Çalışan sağlığının korunması için gerekenlerin yapılması ve sık sık güncellenmesi,

- Çalışma koşullarının sebep olduğu sağlık problemlerinin önlenmesi,

- Çalışanların, sağlık durumlarına olumsuz etki edebilecek unsurlardan korunması ve 
- Çalışanların fiziksel ve ruhsal yapıları açısından kendilerine uygun işlerde çalıştırılması gerekmektedir.

\section{4. İş Sağlı̆̆ı ve Güvenliğinin Önemi}

Daha önce de belirtildiği gibi ilk olarak sanayi devriminden sonra gündeme gelmeye başlayan İSG'nin önemi iş dünyasında günden güne artmaktadır. Özellikle üretimin artması; iş kazaları ve meslek hastalıklarının da artmasının en önemli nedenidir. Önceleri sınırlı sayıda olan meslek hastalıkları radyasyon, kimyasal ürünler, nükleer ürünler gibi üretim teknikleri nedeniyle gitgide artış göstermiştir. $\mathrm{Bu}$ da bu alana verilmesi gereken önem seviyesinin boyutunu ortaya çıkarmıştır. Aksi takdirde iş kazalarının ve meslek hastalıklarının artacağı kolaylıkla söylenebilir (Yiğit, 2011: 4). Zamanının çoğunu iş yerlerinde geçiren çalışanların verimliliği elbette ki iş ortamlarına bağlıdır. Çalışanın verimliliği ve sağ l̆ğ$_{1}$ iç ve dış etkilerden ayrıca kişisel eğilimlerden de etkilenmektedir (Sekulová \& Šimon, 2010: 462).

\section{5. İş Kazaları}

Kaza; toplumsal bir oluşum içinde önceden planlanmayan, bilinmeyen ve kontrol dışına çıkan aynı zamanda çevresine zarar verebilecek nitelikteki olaydır (Yiğit, 2011: 17).

5510 sayılı Sosyal Güvenlik Kanunu'nda iş kazası tanımı şu şekilde yapılmıştır (SSGK, 2018);

a. Sigortalının işyerinde bulunduğu sırada,

b. İşveren tarafından yürütülmekte olan iş nedeniyle sigortalı kendi adına ve hesabına bağımsız çalışıyorsa yürütmekte olduğu iş nedeniyle,

c. Bir işverene bağlı olarak çalışan sigortalının, görevli olarak işyeri dışında başka bir yere gönderilmesi nedeniyle asıl işini yapmaksızın geçen zamanlarda,

d. Bu Kanunun 4'üncü maddesinin birinci fikrasının (a) bendi kapsamındaki emziren kadın sigortalının, iş mevzuatı gereğince çocuğuna süt vermek için ayrılan zamanlarda ve,

e. Sigortalıların, işverence sağlanan bir taşıtla işin yapıldığı yere gidiş gelişi sırasında meydana gelen ve sigortalıyı hemen veya sonradan bedenen ya da ruhen engelli hâle getiren olay şeklinde ifade edilmektedir.

Kazanın cinsine göre iş kazaları aşağıdaki gibi sınıflandırılmaktadır (TMMOB, 2010: 37);

- Düşme ve incinme,

- Parça veya malzeme düşmesi,

- Yanma ve yanık,

- Elektrik kazaları ve

- Patlamalar.

\subsection{Meslek Hastalıkları}

Meslek hastalığı çalışanın işveren emirleri ve direktifleri doğrultusunda çalışırken işin niteliğine veya işin işleyişine göre tekrarlanan, dışsal bir etki sebebiyle ortaya çıkan fiziksel veya ruhsal hastalıklardır (Gerek, 2009: 35).

Meslek hastalıkları, belirli mesleklerde ve sağlıksız koşullarda oluşan ve toplam aktif nüfusa nazaran daha s1k görülen bir hastalıklar grubudur (Güzel, 2013: 347). Meslek hastalıkları; iş ortamından veya işin yapılış biçimine ilişkin sebeplerle, çalışanın yaşadığı geçici veya sürekli hastalık, sakatlık veya ruhsal problemler olarak tanımlanabilir.

Meslek hastalıkları insan vücuduna başlıca 3 yoldan giriş yapmaktadır. Bunlar solunum, emilim ve sindirim yollarıdır. Yani meslek hastalıkları çalışılan ortamdan, solunan havadan, deriden emilim yoluyla veya ağız yoluyla gerçekleşebilmektedir (ÇASGEM, 2013: 40).

Sosyal Sigorta Sağlık İşlemleri Tüzüğü 64. madde'sinde meslek hastalıkları: 
- Kimyasal maddelerle olan meslek hastalıkları,

- Mesleki cilt hastalıkları,

- Pnömokonyozlar ve diğer mesleki solunum sistemi hastalıkları,

- Mesleki bulaşıcı hastalıklar ve

- Fiziki etkenlerle olan meslek hastalıkları olmak üzere 5 kategoride sınıflandırılmıştır.

\section{7. İş Disiplini}

Disiplin kavramı, Türk Dil Kurumu (TDK) sözlüğünde bir topluluğun, yasalarına ve düzenle ilgili yazılı ya da yazısız kurallarına, titizlik ve önemle uyulması durumu, kişilerin içinde yaşadıkları topluluğun genel düşünce ve davranışlarına uymalarını sağlamak amacıyla alınan önlemlerin tümü olarak tanımlanmıştır (TDK, 2018 ).

Bir örgütte işlerin ve örgütün var olan özellikleri çalışan tatminini ve dolayısıyla kaliteyi etkilediğinden dolayı kurumda çalışan ilişkilerini belirli bir düzen ve prosedüre göre yerleştirme gereksinimi doğmuştur. Etkin bir çalışma ilişkileri sistemi oluşturulurken bu sisteme etki eden birçok faktör bulunmaktadır ve bu faktörlerin etki düzeyleri birbirinden farklıdır (Uyargil vd., 2009: 17).

Bir işyerinde çalışma ilişkilerini belirleyen prosedürler şöyle sıralanabilir (W.W.Daniel \& Millward; 1983: 165);

- Yasal Prosedürler,

- Toplu Sözleşmelerle Belirlenen Prosedürler,

- Daha Önceden Kabul edilmiş Yazılı Olan-Olmayan Prosedürler,

- İç Prosedürler,

- Diş Prosedürler,

- Disiplin Prosedürleri şeklindedir.

\subsection{Performans Kavramı ve Performans Türleri}

Performans kavramı bir işletmenin üzerinde durması gereken önemli konulardan bir tanesidir. İşletmenin hedeflerini gerçekleştirebilmesi, yüksek oranlarda kar elde edebilmesi ve bunu devam ettirebilmesi, rekabet ortamında gücünü koruyabilmesi için belirlenmiş standartların altına düşmemesi gerekir. Bunun için de verimlilik ve ölçülen performans kavramına gereken önemi vermelidir.

Gereken bir işi tamamlamak veya kişinin üzerine düşeni etkin bir biçimde meydana getirmesi olarak tanımlanabilen performans, fonksiyonel açıdan tanımlandığında ise önceden belirlenen şartları yerine getirmek suretiyle görevin yerine getirilmesi olarak da tanımlanabilir. Performans kavramı iki şekilde ele alınmaktadır (Gümüştekin ve Öztemiz, 2005: 280);

Nitel Performans; Kurum içindeki rakamsal/somut verilerden daha çok, örgüt içi iletişim, insan kaynakları, müssteri memnuniyeti, ürün kalitesi, yenilik hızı gibi birçok faktörü de içinde barındıran analizleri kapsamaktadır.

Nicel Performans; Klasik süregelmiş olan ve kârlılık oranlarını, ciro rakamlarını, muhasebe kayıtlarını içeren performans türüdür. Nicel performans firmada sadece sayısal değerlerle ilgilendiği için güvenilirliği tartışma konusu olmuştur. Fakat burada unutulmaması gereken nicel performans değerlendirmelerinde yargılar objektif olarak değerlendirilmektedir. Sübjektif değerlendirmelerden uzak olan nicel performans olması istenen ya da hedeflenen amaçlara ne ölçüde ulaşıldığının net sonuçlarını sunar.

\section{9. Çalışan Performansı}

Çalışan Performansı ise kurumda çalışan personelin birçok kriter altında değerlendirilmesi sonucu meydana getirilen performans türüdür. Çalışan performansı tanımlanacak olursa kurum 
içerisinde çalışanların sahip olduğu özelliklerine ve yeteneklerine göre kendilerine verilmiş olan görevleri yerine getirmeleridir (Gümüştekin ve Öztemiz, 2005: 281).

Yapılan çalışmalar işlerinden memnun olan çalışanların işlerinden memnun olmayan çalışanlara oranla, daha yüksek performans gösterdikleri ve o iş yerinde daha uzun süre kaldıklarını göstermiştir (Ivancevich, 2010: 60). $2018: 45)$;

Çalışan performansını etkileyen faktörler maddeler halinde aşağıda belirtilmektedir (Diktaş,

- yetenek,

- eğitim,

- bilgi düzeyi,

- çalışanın kişilik özellikleri,

- yönetim ve çalışan politikası,

- çalışma koşulları,

- organizasyon içi insan ilişkileri,

- çalışanları ödüllendirme ve

- geri bildirim verilmesi şeklindedir.

Etkisi: Erzurum Örneği

\subsection{Araştırmanın Amacı}

Çalışmanın temel amacı, işyerlerinde uygulanan ve uygulanması yasalarla zorunlu hale getirilen İSG uygulamaları ve İş Disiplini uygulamalarının Çalışan Performansı üzerinde etkisinin belirlenmesidir.

Bu temel amacın dışında araştırmanın alt amacı: İSG uygulamalanı ile performans konusunda özellikle yerli literatürde var olan boşluğun giderilmesine katkıda bulunmak, bu konuda yapılacak çalışmalara zemin oluşturarak, çalışmalara öncülük etmektir.

\subsection{Araştırmanın Yöntemi ve Sınırları}

Araştırmada veri toplama yöntemi olarak anket kullanılmıştır. Verilerin toplanmasında, Erzurum ilinde İSG belgesi bulundurma zorunluluğu olan ve çalışan sayısı 50 'nin üzerinde olup çalışmaya katılma noktasında gönüllü 8 firmanın çalışanlarından faydalanılmıştır.

Erzurum'da faaliyet gösteren ve İSG belgesi bulundurma zorunluluğu olan firmaların çalışanlarına olmak üzere toplam 575 çalışan ile yüzyüze görüşme yapılmış ve ankete katılmak istemeyen 65 çalışan hariç 510 çalışan ile anket yapılmıştır. Yani örnek büyüklügüü ankete katılmayı kabul eden çalışanlar olmak üzere 510 dur.

Araştırmada veri ve bilgilerin toplanması için 38 sorudan oluşan anket formu hazırlanmıştır. Anket formu demografik sorular (5), İSG uygulamalarını ölçmeye yönelik sorular (17), İş Disiplinini ölçmeye yönelik sorular (8) ve Çalışan Performnasını ölçmeye yönelik sorular (8) olmak üzere dört kısımdan oluşturulmuştur. Ankette tüm değişkenleri ölçmeye yönelik sorular 5'li Likert ölçeği ile ölçülmüştür. Ölçeği oluşturan değerler; 5- kesinlikle katılıyorum, 4- katılıyorum, 3- fikrim yok, 2katılmıorum ve 1- kesinlikle katılmıyorum şeklindedir.

Ezurumda faaliyet gösteren ve ilgili şartları taşıyan kurumların yetkilileri ile görüşülmüş ve anket izni istenerek yüz yüze görüşme yöntemiyle çalışanlara anketler uygulanmıştır. Öğle aralarında çalışanlar ile anketler tamamlanmış; sunulan hizmetin aksamaması için çalışma saatlerinde devam edilmemiştir. 
Bu araştırmanın dezavantajlarından birisi; anketin Erzurum ilinde uygulanmış olması sonuçların genellenebilirliği açısından olumsuz bir durum teşkil etmektedir. Ancak ileride yapılacak başka araştırmalarda, daha farklı sektörlerde, daha farklı illerde geniş bir ana kütle belirlenip ölçeğin genelleştirilebilmesi mümkündür.

\subsection{Araştırmada Kullanılan Ölçekler ve Araştırma Modeli}

Literatür taraması sonucu Putri ve diğ. 2018 yılında yapmış oldukları (The effect of occupational health and safety, work environment and discipline on employee performance in a consumer goods company) bir çalışmada kullandıkları ölçek, amaca en uygun olduğu düşünüldüğünden uzmanlar tarafından Türkçe 'ye çevrilip, ilgili faktör faktör analizlerinden sonra en son hali ile kullanılmıştır. İlgili ölçek Tablo 1'de görülmektedir.

Tablo 1: Araştırmada Kullanılan Ölçekler

\begin{tabular}{|l|c|c|}
\hline \multicolumn{1}{|c|}{ Ölçek ismi } & Soru sayısı & Kaynak \\
\cline { 1 - 2 } İSG & 17 & \multirow{3}{*}{ Putri, Triatmanto \& Setiyadi (2018) } \\
\cline { 1 - 2 } İS DISSIPLIINI & 8 & \\
\hline ÇALIŞAN PERFORMANSI & 8 & \\
\hline
\end{tabular}

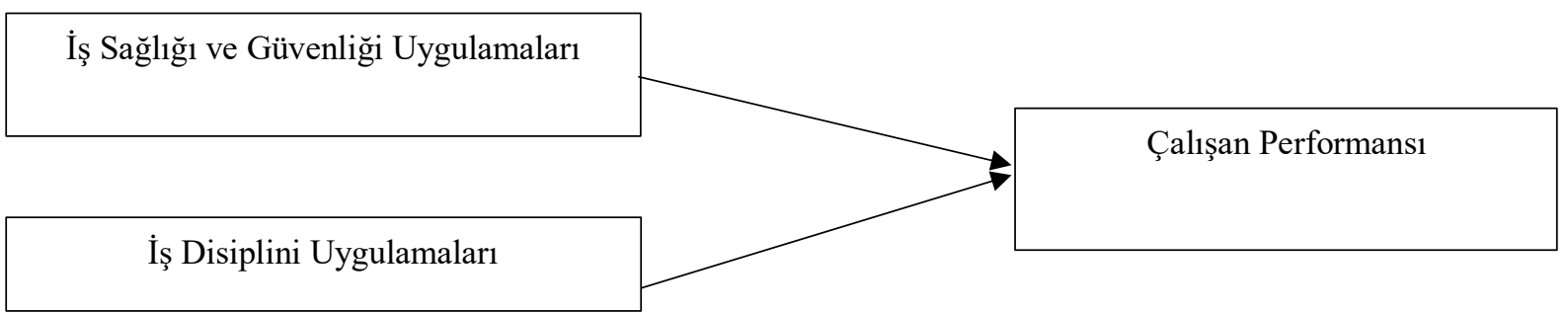

Şekil 1: Araştırmanın Modeli

Şekil 1 de görüldüğü gibi araştırma modeli 3 temel değişkenden oluşmaktadır. İSG uygulamaları; sağlık ve güvenlik bilgisi, sağlık durumu, sağlık ve güvenlik güvencesi, iş ekipmanları, koruyucu ekipmanlar, işyeri durumu, işyeri Güvenliği ve çalışan ilişkilerinden oluşmaktadır. İş Disiplini değişkenleri kurallara itaat, çalışma saatlerine itaat, işyeri kullanımı ve prosedüre göre çalışmadan oluşmaktadır. Son olarak Çalışan Performansı ise iş kalitesi, iş miktarı, iş tutumu ve mesleki ilgi alanlarından meydana gelmektedir.

\subsection{Araștırmanın Hipotezleri}

$\mathrm{Bu}$ çalışmada İş Sağlığı ve Güvenliği uygulamaları ve İş Disiplini faktörlerinin Çalışan Performansına etkisi incelenmektedir. Ayrıca İSG uygulamaları, İş Disiplini ve Çalışan Performansının sektörlere göre farklılığı test edilmektedir. $\mathrm{Bu}$ anlamda araştırma hipotezleri aşağıdaki gibi belirlenmiştir.

$H_{I}$ : Mamul sektöründe İş Sağlığı ve Güvenliği uygulamaları Çalışan Performansını pozitif yönde etkilemektedir.

$\mathrm{H}_{2}$ : Mamul sektöründe İş Disiplini uygulamaları Çalışan Performansını pozitif yönde etkilemektedir.

$H_{3}$ : Hizmet sektöründe İş Sağlığı ve Güvenliği uygulamaları Çalışan Performansını pozitif yönde etkilemektedir. etkilemektedir.

$H_{4}$ : Hizmet sektöründe İş Disiplini uygulamaları, Çalışan Performansını pozitif yönde 
$H_{5}$ : Mamul ve hizmet sektörü arasında İş Sağlı̆̆ı ve Güvenliği uygulamaları istatistiksel olarak anlamlı bir şekilde farklılık göstermektedir.

$H_{6}$ : Mamul ve hizmet sektörü arasında İş Disiplini uygulamaları istatistiksel olarak anlamlı bir şekilde farklılık göstermektedir.

$H_{7}$ : Mamul ve hizmet sektörü arasında Çalışan Performansı istatistiksel olarak anlamlı bir şekilde farklılık göstermektedir.

\subsection{Analizler ve Bulgular}

Araştırmada toplanan veriler analiz edilmeden önce verilerin normallik testleri yapılmış ve bu verilerin niteliği esas alınarak parametrik testler uygulanmıştır. Çalışmada öncelikle değişkenler arasında ilişkinin varlığını belirlemek amacıyla korelasyon testleri yapılmış, elde edilen sonuçlara istinaden çoklu regresyon analizleri yapılmıştır. Sektörler arasındaki farklılığı ölçmek amacıyla ise t testi uygulanmıştır. Çalışmada ayrıca demografik verilerin ve anket sorularının analizi için; frekans dağılımları, standart sapma ve aritmetik ortalama testleri kullanılmıştır. Analizler SPSS 20.0 istatistik paket programı kullanılarak gerçekleştirilmiştir. Analizler ve yorumlar, araştırma modeli çerçevesinde alt başlıklar halinde aşağıda sıralanmıştır.

\subsection{Kullanılan Ölçeklerin Güvenilirliklerinin Belirlenmesi}

Çalışmada İSG uygulamaları, İş Disiplini ve Çalışan Performansı değişkenleri için kullanılan ölçeklerin güvenilirlik düzeylerinin belirlenmesi amacıyla Cronbach's Alpha değerlerine bakılmış ve elde edilen sonuçlar Tablo 2'de sunulmuştur.

Tablo 2: Çalışmada Kullanılan Ölçeklerin Güvenilirlik Düzeyleri

\begin{tabular}{|l|c|c|}
\hline \multicolumn{1}{|c|}{ Ölçek } & \multicolumn{2}{c|}{ Alfa } \\
\hline & Mamul & Hizmet \\
\hline İSG &, 821 &, 748 \\
\hline İş Disiplini &, 726 &, 733 \\
\hline Çalışan Performans1 &, 831 &, 782 \\
\hline
\end{tabular}

Tablo 2'de görüleceği üzere çalışmada kullanılan tüm ölçeklerin genel olarak güvenilirlik düzeyleri beklenen ve literatürde yaygın olarak kabul edilen değerden (0.70) yüksek çıkmıştır. Dolayısıyla çalışmanın ölçeklerinin güvenilir olduğu sonucuna varılmıştır.

\subsection{Katılımcıların Demografik Özelliklerinin Analizi} edilmiştir.

Katılımc1ların demografik özellikleri analiz edildiğinde Tablo 3 de yer alan veriler elde 


\begin{tabular}{|c|c|c|c|c|c|}
\hline & & \multicolumn{2}{|c|}{ Mamul } & \multicolumn{2}{|c|}{ Hizmet } \\
\hline & & $\mathrm{n}$ & $\%$ & $\mathrm{n}$ & $\%$ \\
\hline \multirow[t]{2}{*}{ Cinsiyet } & Kadın & 26 & 10,0 & 96 & 38,4 \\
\hline & Erkek & 234 & 90,0 & 154 & 61,6 \\
\hline & & 260 & 100 & 250 & 100 \\
\hline \multirow[t]{2}{*}{ Medeni durum } & Evli & 202 & 77,7 & 161 & 64,4 \\
\hline & Bekâr & 58 & 22,3 & 89 & 35,6 \\
\hline & & 260 & 100 & 250 & 100 \\
\hline \multirow{5}{*}{ Yaş } & $17-26$ & 20 & 7,7 & 24 & 9,6 \\
\hline & $27-36$ & 82 & 31,5 & 136 & 54,4 \\
\hline & $37-46$ & 144 & 55,4 & 82 & 32,8 \\
\hline & $47-56$ & 14 & 5,4 & 8 & 3,2 \\
\hline & $57-+$ & - & - & - & - \\
\hline & & 260 & 100 & 250 & 100 \\
\hline \multirow{5}{*}{ Eğitim } & İlköğretim & 28 & 10,8 & 26 & 10,4 \\
\hline & Lise & 124 & 47,7 & 49 & 19,6 \\
\hline & Yüksekokul & 33 & 12,7 & 27 & 10,8 \\
\hline & Üniversite & 60 & 23,0 & 135 & 54,0 \\
\hline & Lisansüstü & 15 & 5,8 & 13 & 5,2 \\
\hline & & 260 & 100 & 250 & 100 \\
\hline \multirow[t]{3}{*}{ Çalıştığı yıl } & $1-5$ & 80 & 30,8 & 122 & 48,8 \\
\hline & $6-10$ & 77 & 29,6 & 99 & 39,6 \\
\hline & 11-+ & 103 & 39,6 & 29 & 11,6 \\
\hline & & 260 & 100 & 250 & 100 \\
\hline
\end{tabular}

Tablo 3'den anlaşılacağı gibi araştırmaya konu olan katılımcıların cinsiyetleri göz önüne alındığında inceleme sonucunda mamul sektöründe katılımcıların çoğunluğunun $(\% 90,0)$ erkeklerden oluştuğu; hizmet sektöründe de çoğunluğun $(\% 61,6)$ aynı şekilde erkeklerden oluştuğu tespit edilmiştir.

Katılımcıların medeni durumları incelendiğinde mamul sektöründe çalışanların $(\% 77,7)$ ve hizmet sektöründe çalışanların $(\% 64,4)$ ile evli olduğu anlaşılmaktadır.

Ankete katılanların yaş dağılımları incelendiğinde mamul sektöründe çalışanların çoğunluğunun 37-46 yaş $(\% 55,4)$ arası olduğu; hizmet sektöründe ise çoğunluğun 27-36 yaş $(\% 54,4)$ arası olduğu anlaşı1mıştır.

Katılımcıların eğitim durumları incelendiğinde mamul sektöründe lise mezunlarının çoğunlukta $(\% 47,7)$ olduğu; hizmet sektöründe ise $(\% 54,0)$ üniversite mezunlarının çoğunlukta olduğu görülmektedir.

Katılımcıların çalıştıkları yıllar demografik veriler başığı altında sorulmuştur. Veriler incelendiğinde ise sektörler arasında ciddi farklılık olduğu anlaşılmıştır. Mamul sektöründe çalışanların büyük çoğunluğu $(\% 39,6)$ kurumda 11 yıl ve üzeri çalıştığını belirtmiştir. Oysaki hizmet sektöründe çalışanlar $(\% 48,8)$ çalışma yıllarını 1-5 yıl olarak belirtmişlerdir.

\section{8. İş Sağlığı ve Güvenliğinin Uygulama Düzeyini Belirlemeye Yönelik İfadelerin Ortalama ve Standart Sapma Değerleri}

Araştırma kapsamında İş Sağlığı ve Güvenliği ile ilgili bilgi ve uygulama düzeyini belirlemeye yönelik ifadeler değerlendirilmiş, ortalama ve standart sapma değerleri Tablo 4'de verilmiştir. 
Tablo 4: İSG İfadelerinin Ortalama ve Standart Sapma Değerleri

\begin{tabular}{|c|c|c|c|c|}
\hline \multirow[t]{2}{*}{ İș Sağlığı ve Güvenliği Değişkenleri } & \multicolumn{2}{|c|}{ Mamul } & \multicolumn{2}{|c|}{ Hizmet } \\
\hline & Ortalama & St. Sap. & Ortalama & St. Sap. \\
\hline $\begin{array}{l}\text { Her çalışanın İş Sağlığı ve Güvenliği konusunda bilgisi } \\
\text { vardır. }\end{array}$ & 4,28 & 0,82 & 3,52 & 0,78 \\
\hline $\begin{array}{l}\text { Kurum çalışanlarına İş Sağlığı ve Güvenliği eğitimi } \\
\text { verilmektedir. }\end{array}$ & 4,38 & 0,84 & 3,73 & 0,77 \\
\hline Her çalışanın sağlığı iyi durumdadır. & 3,80 & 0,93 & 3,36 & 0,88 \\
\hline $\begin{array}{l}\text { Çalışma süresi çalışanın sağlık koşullarına uygun } \\
\text { yapılır. }\end{array}$ & 4,02 & 0,86 & 3,52 & 0,87 \\
\hline Kurum tüm çalışanlarına sağlık güvencesi sağlar. & 4,42 & 0,66 & 4,32 & 0,48 \\
\hline $\begin{array}{l}\text { Kurum herhangi bir kaza durumunda ilk yardım } \\
\text { sağlayabilmektedir. }\end{array}$ & 4,39 & 0,58 & 4,40 & 0,52 \\
\hline $\begin{array}{l}\text { Kurum herhangi bir kaza durumunda çalışanın } \\
\text { hastaneye sevkini sağlar. }\end{array}$ & 4,48 & 0,56 & 4,40 & 0,51 \\
\hline Kullanılan makine ve teçhizat işi yapmaya uygundur. & 4,38 & 0,56 & 4,04 & 0,46 \\
\hline $\begin{array}{l}\text { İş ekipmanlarının durumu iyi ve kullanılabilir } \\
\text { durumdadır. }\end{array}$ & 4,37 & 0,62 & 4,06 & 0,49 \\
\hline Kazaları önlemek için koruyucu ekipmanlar mevcuttur. & 4,44 & 0,62 & 4,19 & 0,48 \\
\hline $\begin{array}{l}\text { Kazaları önlemek için tüm tehlikeli ekipmanlarda uyarı } \\
\text { işaretleri mevcuttur. }\end{array}$ & 4,45 & 0,53 & 4,20 & 0,51 \\
\hline Kurum daima temiz ve çalışmaya elverişlidir. & 4,00 & 0,91 & 4,06 & 0,63 \\
\hline $\begin{array}{l}\text { Makina ve iş ekipmanının yerleşim düzeni çalışmayı } \\
\text { kolaylaştırır. }\end{array}$ & 4,24 & 0,73 & 4,10 & 0,63 \\
\hline $\begin{array}{l}\text { Çalışma ortamı işçinin kendini güvende hissedebileceği } \\
\text { şekilde tasarlanmıştır. }\end{array}$ & 4,06 & 0,79 & 3,93 & 0,68 \\
\hline $\begin{array}{l}\text { Kurum, Güvenliği sağlayacak önlemler almakta ve } \\
\text { denetlemektedir. }\end{array}$ & 4,35 & 0,59 & 4,10 & 0,66 \\
\hline $\begin{array}{l}\text { Çalışma arkadaşları ile rahatlıkla iletişim kurulabilecek } \\
\text { ve işbirliği yapılabilecek ortam vardır. }\end{array}$ & 4,20 & 0,72 & 3,75 & 0,76 \\
\hline Çalıșma ortamında aile sıcaklığı mevcuttur. & 3,87 & 0,96 & 3,55 & 0,98 \\
\hline Genel Ortalama & 4,24 & 0,72 & 3,95 & 0,65 \\
\hline
\end{tabular}

Tablo 4 incelendiğinde İş Sağlığı ve Güvenliği konusunda mamul sektörünün 4,24 ile ortalamanın çok üzerinde olduğu ve bu konuda bilgi ve uygulama düzeyinin yeterli seviyede olduğu tespit edilmiştir. Hizmet sektörüne bakıldığında bu oranın 3,95 ile ortalamanın üzerinde olduğu fakat mamul sektörü ile karşılaştırıldığında daha az olduğu sonucu ortaya çıkmıştır.

\section{9. İş Disiplinine İlişkin İfadelerin Ortalama ve Standart Sapma Değerleri}

Araştırma kapsamında İş Disiplini uygulamaları ile ilgili bilgi ve uygulama düzeyini belirlemeye yönelik ifadeler değerlendirildiğinde elde edilen ortalamalar ve standart sapmalar Tablo 5 'de verilmiştir. 
Tablo 5: İş Disiplini İfadelerinin Ortalama ve Standart Sapma Değerleri

\begin{tabular}{|l|c|c|c|c|}
\hline \multicolumn{1}{|c|}{ İş Disiplini Değişkenleri } & \multicolumn{2}{c|}{ Mamul } & \multicolumn{2}{c|}{ Hizmet } \\
\hline $\begin{array}{l}\text { Kurumun belirlediği kurallara ve düzenlemelere } \\
\text { uyulmaktadır. }\end{array}$ & Ortalama & St. Sap. & Ortalama & St. Sap. \\
\hline $\begin{array}{l}\text { İş ortamında çalışanlar kendilerine belirtilmiş olan } \\
\text { görevleri yapmaktan sorumludurlar. }\end{array}$ & 4,33 & 0,61 & 4,00 & 0,61 \\
\hline İşe her zaman zamanında gelinir. & 4,37 & 0,72 & 4,04 & 0,67 \\
\hline $\begin{array}{l}\text { Kurumda, daha önceden belirlenen çalışma saatlerine } \\
\text { uygun olarak çalışılmaktadır. }\end{array}$ & 4,43 & 0,57 & 4,08 & 0,49 \\
\hline $\begin{array}{l}\text { İşyeri ve iş için gerekli olan altyapapı hizmetleri } \\
\text { ihtiyaçlara uygun olarak tasarlanmıştır. }\end{array}$ & 4,19 & 0,68 & 4,19 & 0,65 \\
\hline Çalışma saatleri dışında işyeri kullanıma açık değildir. & 4,01 & 1,04 & 3,96 & 0,64 \\
\hline İş yapılırken ilgili çalışma prosedürleri uygulanır. & 4,33 & 0,62 & 4,04 & 0,58 \\
\hline $\begin{array}{l}\text { Uygulanan prosedürler zevkli bir çalışma ortamının } \\
\text { oluşmasına yardımcı olur. }\end{array}$ & 3,99 & 0,84 & 3,86 & 0,78 \\
\hline Genel ortalama & $\mathbf{4 , 2 4}$ & $\mathbf{0 , 7 0}$ & $\mathbf{4 , 0 3}$ & $\mathbf{0 , 6 5}$ \\
\hline
\end{tabular}

Tablo 5 incelendiğinde genel ortalamaların 4'ün üzerinde bir değer aldığı tespit edilmiştir. Elde edilen bu değerler sektörlerin İş Disiplini konusunda yeteri kadar başarılı olduklarını göstermektedir.

\subsection{Performansa İlişkin İfadelerin Ortalama ve Standart Sapma Değerleri}

Araştırma kapsamında performans düzeyini belirlemeye yönelik ifadeler değerlendirildiğinde elde edilen ortalama ve standart sapma değerleri Tablo 6'da verilmiştir.

Tablo 6: Performans İfadelerinin Ortalama ve Standart Sapma Değerleri

\begin{tabular}{|l|c|c|c|c|}
\hline Çalışan Performansı Değişkenleri & \multicolumn{2}{|c|}{ Mamul } & \multicolumn{2}{c|}{ Hizmet } \\
\hline $\begin{array}{l}\text { 1. İşyeri faaliyetleri kanunlarla belirtilen kalite } \\
\text { standartları ölçüsünde gerçekleşir. }\end{array}$ & 4,30 & 0,61 & 4,30 & 0,61 \\
\hline $\begin{array}{l}\text { 2. Kaliteli bir iş yapmak, bunu devam ettirmek ve } \\
\text { denetlemek için gerekenler yapılmaktadır. }\end{array}$ & 4,33 & 0,72 & 4,31 & 0,67 \\
\hline $\begin{array}{l}\text { 3. Kurumun belirlediği hedefler ulaşılabilir } \\
\text { niteliktedir. }\end{array}$ & 4,37 & 0,57 & 4,22 & 0,68 \\
\hline $\begin{array}{l}\text { 4. Kurum, üretim performansınını arttırabileceği } \\
\text { gerekli potansiyele sahiptir. }\end{array}$ & 4,43 & 0,57 & 4,33 & 0,66 \\
\hline $\begin{array}{l}\text { 5. Kurumda, yöneticiler ve çalışanlar yaptıkları işe } \\
\text { karşı pozitif bir tutum içerisindedirler. }\end{array}$ & 4,19 & 0,68 & 4,01 & 0,81 \\
\hline $\begin{array}{l}\text { 6. Çalışırken ortaya çıkan sorunların çözümü için } \\
\text { gereken özveri gösterilir. }\end{array}$ & 4,01 & 1,04 & 4,17 & 0,70 \\
\hline $\begin{array}{l}\text { 7. Çalışanlar, kurumda uzmanlık alanlarına göre } \\
\text { yerleştirilmişlerdir. }\end{array}$ & 4,33 & 0,62 & 4,07 & 0,73 \\
\hline $\begin{array}{l}\text { 8. Kurumda çalı̧anlar işlerini tutkuyla } \\
\text { yapmaktadırlar. }\end{array}$ & 3,99 & 0,84 & 4,10 & 0,76 \\
\hline Genel Ortalama & $\mathbf{4 , 2 4}$ & $\mathbf{0 , 7 0}$ & $\mathbf{4 , 1 8}$ & $\mathbf{0 , 7 0}$ \\
\hline
\end{tabular}

Tablo 6 incelendiğinde her iki sektörde ortalamanın 4'ün üzerinde bir değer aldıkları görülmektedir. Bu sonuçlara istinaden sektörlerin çalışan performansı konusunda yeterli oldukları ifade edilebilir.

\subsection{1. İSG ve İş Disiplini Uygulamalarının Çalışan Performansı Üzerine Etkisinin Belirlenmesi}

Araştırma modeline göre Çalışan Performansı, İş Sağlığı ve Güvenliği uygulamaları ile İş̧ Disiplini uygulamaları tarafından etkilenmektedir. Bu etkileşimin incelenmesi için çoklu regresyon 
analizi yapılmıştır. Bu analizde İSG uygulamaları ile İş Disiplini bağımsız, çalışan performansı ise bağımlı değişken olarak analize alınmıştır. Çoklu regresyon analizi sonuçları Tablo 7'de gösterilmiştir.

Tablo 7: Mamûl Sektörü Çoklu Regresyon Analizi

\begin{tabular}{|c|c|c|c|c|c|}
\hline \multirow[t]{2}{*}{$\begin{array}{l}\text { Bağımlı Değişken: } \\
\text { Çalışan Performansı }\end{array}$} & $\mathbf{R}$ & $\mathbf{R}^{2}$ & Düzeltilmiş $\mathbf{R}^{2}$ & \multicolumn{2}{|c|}{$\begin{array}{c}\text { Tahmini Standart } \\
\text { Hatası }\end{array}$} \\
\hline & 0,692 & 0,479 & 0,475 & \multicolumn{2}{|c|}{0,347} \\
\hline$\overline{\text { ANOVA }}$ & $\begin{array}{l}\text { Kareler } \\
\text { Toplamı }\end{array}$ & $\begin{array}{l}\text { Serbestlik } \\
\text { Derecesi }\end{array}$ & Kareler Ortalaması & F değeri & $\mathbf{P}$ \\
\hline Regresyon & 28,496 & 2 & 14,248 & 118,286 & 0,000 \\
\hline Artıklar & 30,956 & 257 & 0,120 & $*$ & * \\
\hline Toplam & 59,452 & 259 & $*$ & * & * \\
\hline \multirow[t]{2}{*}{$\begin{array}{l}\text { Bağımsız Değişkenler: } \\
\text { İSG, İş Disiplini }\end{array}$} & \multicolumn{2}{|c|}{$\begin{array}{c}\text { Standartlaştırılmamış } \\
\text { Katsayılar }\end{array}$} & $\begin{array}{c}\text { Standartlaştırılmış } \\
\text { Katsayılar }\end{array}$ & \multirow[t]{2}{*}{$t$ değeri } & \multirow[t]{2}{*}{$\mathbf{P}$} \\
\hline & B & $\begin{array}{l}\text { Standart } \\
\text { Hata }\end{array}$ & Beta & & \\
\hline Sabit & 0,329 & 0,258 & * & 1,276 & 203 \\
\hline İSG & 0,388 & 0,072 & 0,305 & 5,357 & 000 \\
\hline \multirow[t]{2}{*}{ İş Disiplini } & 0,522 & 0,064 & 0,462 & 8,113 &, 000 \\
\hline & \multicolumn{3}{|c|}{ Korelasyonlar } & \multicolumn{2}{|c|}{$\begin{array}{c}\text { Çoklu Doğrusallık } \\
\text { İstatistikleri }\end{array}$} \\
\hline Bağımsız Değişkenler & $\begin{array}{l}\text { Zero - } \\
\text { order }\end{array}$ & Partial & Part & Tolerence & $\begin{array}{l}\text { VIF } \\
\end{array}$ \\
\hline İSG & 0,588 & 0,317 & 0,241 & 0,625 & 1,601 \\
\hline İs Disiplini & 0,649 & 0,452 & 0,365 & 0,625 & 1,601 \\
\hline
\end{tabular}

Tablo 7'de görüldüğü gibi yapılan çoklu regresyon analizinde mamul sektörü 0,01 önem düzeyinde anlamlı çıkmıştır. İSG uygulamaları ve İş Disiplini uygulamalarının çalışan performansını açıklayıcılık gücü \%47,9 olarak tespit edilmiştir.

İSG'nin çalışan performansı üzerinde 0,01 önem düzeyinde pozitif anlamlı bir etkiye sahip olduğu $(\mathrm{B}=0,388 ; \mathrm{p}=0,000)$, diğer yandan İs Disiplini uygulamalarının çalışan performansı üzerinde 0,01 önem düzeyinde anlamlı bir pozitif etkiye sahip olduğu $(B=0,522 ; p=0,000)$ görülmektedir. $B u$ kapsamda, İSG de meydana gelen 1 birimlik bir artışın çalışan performansını 38 birim arttırdığ 1 ; buna karşı1ık İş Disiplini uygulamalarındaki 1 birimlik bir artışın çalışan performansını 52 birim arttırdığ sonucuna ulaşılmaktadır. Buna göre İSG uygulamaları ve İş Disiplini uygulamaları arttıkça çalışan performansı artmaktadır. Elde edilen bu sonuç teorik yapıyı da desteklemektedir.

$\mathrm{Bu}$ sonuçlar doğrultusunda, mamul sektöründe İSG uygulamaları ve İş Disiplini uygulamalarının çalışan performansı üzerinde etkili olduğunu öngören $\mathrm{H}_{1}$ ve $\mathrm{H}_{2}$ hipotezleri kabul edilmiştir. 


\begin{tabular}{|c|c|c|c|c|c|}
\hline \multicolumn{6}{|c|}{ Tablo8: Hizmet Sektörü Çoklu Regresyon Analizi } \\
\hline $\begin{array}{l}\text { Bağımlı Değişken: } \\
\text { Çalışan Performansı }\end{array}$ & $\mathbf{R}$ & $\mathbf{R}^{2}$ & Düzeltilmiş $\mathbf{R}^{2}$ & \multicolumn{2}{|c|}{$\begin{array}{c}\text { Tahmini Standart } \\
\text { Hatası }\end{array}$} \\
\hline & 0,451 & 0,203 & 0,197 & \multicolumn{2}{|c|}{, 414} \\
\hline ANOVA & $\begin{array}{l}\text { Kareler } \\
\text { Toplamı }\end{array}$ & $\begin{array}{l}\text { Serbestlik } \\
\text { Derecesi }\end{array}$ & Kareler Ortalaması & F değeri & $\mathbf{P}$ \\
\hline Regresyon & 10,824 & 2 & 5,412 & 31,490 & 0,000 \\
\hline Artıklar & 42,451 & 247 & 0,172 & $*$ & $*$ \\
\hline Toplam & 53,275 & 249 & $*$ & $*$ & $*$ \\
\hline \multirow[t]{2}{*}{$\begin{array}{l}\text { Bağımsız Değişkenler: } \\
\text { İSG, İş Disiplini }\end{array}$} & \multicolumn{2}{|c|}{$\begin{array}{c}\text { Standartlaştırılmamış } \\
\text { Katsayılar }\end{array}$} & $\begin{array}{c}\text { Standartlaştırılmış } \\
\text { Katsayılar }\end{array}$ & \multirow[t]{2}{*}{ t değeri } & \multirow[t]{2}{*}{$\mathbf{P}$} \\
\hline & B & $\begin{array}{c}\text { Standart } \\
\text { Hata }\end{array}$ & Beta & & \\
\hline Sabit & 0,256 & 0,485 & $*$ & 0,528 & 0,598 \\
\hline İSG & 0,544 & 0,088 & 0,354 & 6,163 & 0,000 \\
\hline \multirow[t]{2}{*}{ İş Disiplini } & 0,391 & 0,098 & 0,230 & 4,001 & 0,000 \\
\hline & \multicolumn{3}{|c|}{ Korelasyonlar } & \multicolumn{2}{|c|}{$\begin{array}{c}\text { Çoklu Doğrusallık } \\
\text { İstatistikleri }\end{array}$} \\
\hline Bağımsız Değişkenler & $\begin{array}{l}\text { Zero - } \\
\text { order }\end{array}$ & Partial & Part & Tolerence & VIF \\
\hline İSG & 0,389 & 0,365 & 0,350 & 0,977 & 1,024 \\
\hline İş Disiplini & 0,284 & 0,247 & 0,227 & 0,977 & 1,024 \\
\hline
\end{tabular}

Hizmet sektörü için İSG uygulamaları ile iş disiplininin çalışan performansı üzerindeki etkisini belirlemek için çoklu regresyon analizi yapılmış değerler Tablo 8'da gösterilmiştir.

Tablo 8'de görüldüğü gibi yapılan çoklu regresyon analizi sonucunda hizmet sektörü de 0,01 önem seviyesinde anlamlı çıkmıştır. Tablo 8'den İSG uygulamaları ve İş Disiplini uygulamalarının çalışan performansını açılayıcılık gücü \%20,3 olarak tespit edilmiştir. İSG'nin çalışan performansı üzerinde 0,01 önem düzeyinde pozitif anlamlı bir etkiye sahip olduğu $(B=0,544 ; p=0,000)$, diğer yandan İş Disiplini uygulamalarının çalışan performansı üzerinde 0,01 önem düzeyinde anlamlı bir pozitif etkiye sahip olduğu $(\mathrm{B}=0,391 ; \mathrm{p}=0,000)$ görülmektedir. Yani, İSG de meydana gelen 1 birimlik bir artışın çalışan performansını 54 birim arttırdığ ; buna karşılık İş Disiplini uygulamalarındaki 1 birimlik bir artışın çalışan performansını 39 birim arttırdığı sonucuna ulaşılmaktadır. Buna göre İSG uygulamaları ve İş Disiplini uygulamaları arttıkça çalışan performansı artmaktadır. Bu sonuç teorik yapıyı da desteklemektedir. Bu veriler 1şığında, hizmet sektöründe İSG uygulamaları ve İş Disiplini uygulamalarının çalışan performansı üzerinde etkili olduğunu öngören $\mathrm{H}_{3}$ ve $\mathrm{H}_{4}$ hipotezleri kabul edilmiştir.

Sektörler arasında ayrım yapmadan İSG ve İş Disiplininin çalışan performansı üzerinde 0,01 önem düzeyinde pozitif anlamlı bir etkiye sahip olup olmadığını belirlemek amacıyla yapılan regresyon testinde anlamlı bir etkinin var olduğu belirlenmiştir $(P=0,000)$. İSG ve İş Disiplini uygulamalarının sektör ayrımı yapılmaksızın çalışan performansı üzerinde etkisi olduğu tespit edilmiştir.

\subsection{Sektörler Arası İSG-İş̧ Disiplini ve Çalışan Performansının Farklılığı̆ın Test Edilmesi}

Sektörler arasında İSG, İş Disiplini ve Çalışan Performansının farklılığının test edilmesi amacıyla t testi yapılmış ve ilgili sonuçlar Tablo 9 da gösterilmiştir. 


\begin{tabular}{|c|c|c|c|c|c|c|}
\hline \multicolumn{7}{c}{ Tablo 9: Sektörler Arası Farklılığın Test Edilmesi } \\
\hline & $\mathrm{F}$ & $\mathrm{t}$ & $\mathrm{df}$ & Anlamlılı & Ort. Fark1 & St. Sap. Fark1 \\
\hline İSG & 10,565 & 9,542 & 491,867 & 0,000 & 0,287 & 0,030 \\
\hline İş Disiplini & 50,345 & 6,889 & 443,604 & 0,000 & 0,216 & 0,031 \\
\hline $\begin{array}{c}\text { Çalışan } \\
\text { Perf. }\end{array}$ & 1,002 & 5,019 & 508 & 0,000 & 0,209 & 0,041 \\
\hline
\end{tabular}

Tablo 9'da görüldüğü gibi mamul ve hizmet sektörü arasında İSG uygulamaları arasında ortalamalara ilişkin $(p<0.05)$ istatistiksel bir farklılığın var olduğu tespit edilmiştir. Mamul sektörünün hizmet sektöründen daha yüksek bir ortalamaya sahip olduğu tespit edilmiştir $(0,287)$. Bu sonuca göre, İSG uygulamaları sektörler arasında anlamlı bir farklılık göstermektedir. $\mathrm{Bu}$ anlamda $\mathrm{H}_{5}$ hipotezi kabul edilmiştir.

Tablo 9'da görüldüğü gibi mamul ve hizmet sektörü arasında İş Disiplini uygulamaları arasında ortalamalara ilişkin $(p<0.05)$ istatistiksel bir farklılığın var olduğu tespit edilmiştir. Mamul sektörünün hizmet sektöründen daha yüksek bir ortalamaya sahip olduğu tespit edilmiştir $(0,216)$. Bu sonuca göre, İş Disiplini uygulamaları sektörler arasında anlamlı bir farklılık göstermektedir. Bu anlamda $\mathrm{H}_{6}$ hipotezi kabul edilmiştir.

Tablo 9'da görüldüğü gibi mamul ve hizmet sektörünün çalışan performansı konusunda ortalamalara ilişkin $(p<0.05)$ istatistiksel bir farklılı̆̆ın var olduğu görülür. Mamul sektörünün hizmet sektöründen daha yüksek bir ortalamaya sahip olduğu tespit edilmiştir $(0,209)$. Bu sonuca göre, çalışan performansı uygulamaları sektörler arasında anlamlı bir farklılık göstermektedir. $\mathrm{Bu}$ anlamda $\mathrm{H}_{7}$ hipotezi kabul edilmiştir.

\section{Sonuç ve Öneriler}

Son yıllarda ülkemizde sıkça duyulmaya başlayan İSG literatürde de gereken ilgiyi görmüştür. Literatür tarandığı zaman bu alanda birçok çalışmanın olduğu görülmektedir. Fakat ilgili literatür incelendiğinde yoğunluğun sağlık sektörüne kaydığı anlaşılmaktadır. (Tüzüner \& Özaslan, 2011; hastanelerde İSG ile ilgili bir değerlendirme yapmıştır), (Ceylan, 2012; İSG eğitim sorunları ve çözüm önerileri üzerine bir çalışma yapmıştır), (Meydanlıŏglu ,2013; sağlık çalışanlarının sağlı̆̆ 1 ve güvenliği üzerine çalışmıştır), (Çopur vd. 2006; bir hastanede çalışanların İSG görüşlerini incelemiştir), (Solmaz \& Solmaz, 2017; hastanelerde İSG üzerine bir çalışma yapmıştır), (Sunar \& Çınar, 2017; hastane çalışanlarının İş Sağlığı ve Güvenliğini incelemiştir), (Uçak, 2009; sağlı personelinin iş kazalarının geri bildirimini incelemiştir) vb.

Ayrıca çalışan performansına etki eden faktörler üzerine de literatürde bir hayli çalışma (Kesen, 2015, Örgütsel Demokrasinin çalışan performansına etkisi), (Pekdemir vd., 2014,ödüllendirmenin çalışan performansına etkisi), (Korkmazer vd. 2016, psikolojik sermayenin çalışan performansına etkisi), (Doğanay \& Şen, 2014, Liderlik Tarzlarının çalışan performansına etkisi), (Tanrıverdi vd. 2010, iletişim becerilerinin çalışan performansına etkisi), (Ahmet, 2016, Eğitimin çalışan performansı üzerine etkisi) yer almasına rağmen ISSG 'nin Çalışan Performansına etkisini inceleyen çalışma bir haylı azdır. $\mathrm{Bu}$ çalışma literatürde yer alan bu boşluğu doldurması nedeniyle özgün olarak değerlendirilebilir.

İş Sağlığı ve Güvenliği uygulamaları ile İş Disiplini uygulamalarının çalışan performansı üzerinde etkisinin belirlenmeye çalışıldığı bu araştırma Erzurum ilinde faaliyet gösteren işletmelerde gerçekleştirilmiş ve toplanan bilgilerin analiz edilmesiyle şu sonuçlara ulaşılmıştır.

- Eğitim durumu açısından hizmet sektörünün daha kalifiye elemana ihtiyaç duyduğu anlaşılmaktadır. Çalışılan yıl açısından üretim sektörünün var olan çalışanıyla uzun süre yoluna devam edebildiği fakat hizmet sektöründe çalışan sirkülasyonunun hızlı olduğu sonucuna varılmıştır. 
- İş Sağlığı ve Güvenliği ile ilgili değişkenlerde mamul sektörünün ortalamasının $(4,24)$ hizmet sektörü ortalamasından $(3,95)$ daha yüksek bir ortalamaya sahip olduğu tespit edilmiştir. İş Sağlığı ve Güvenliği konusunda mamul sektöründekilerin eğitim düzeylerinin daha düşük olmasına rağmen bu konuda daha fazla bilgi sahibi oldukları tespit edilmiştir. Mamul sektörünün hizmet sektörüne oranla daha riskli işler yapması ve sürekli bu risklerle çalışması mamul sektöründe bu alanda bilinç ve farkındalığı artırdığı söylenebilir.

- Çalışma sürelerinin çalışanın sağlık koşullarına uygun yapılıp yapılmadığı konusunda mamul sektörü ortalamanın üzerine çıkarken, hizmet sektörü çok daha gerilerde kalmıştır. Mamul sektöründe çalışma süreleri konusunda toleransın mümkün olduğu fakat hizmet sektöründe bu konuda daha katı davranıldığ sonucuna ulaşılmıştır.

- İş Disiplini konusunda uygulanan prosedürlerin her iki sektörde de zevkli bir çalışma ortamı oluşturmadığ istenilerek değil zoraki bir şekilde uygulandığı sonucu anlaşılmıştır. Bu değişkene ait soruların tamamında mamul sektörünün hizmet sektöründen daha başarılı olduğu ve sistemin çalışanlar tarafından kabullenilip daha yerleşmiş olduğu sonucuna ulaşılmıştır.

- Araştırma modelinde yer alan değişkenler arasında ilişkilerin analiz edilmesi sonucu iş Sağlığı ve Güvenliği uygulamaları ile İş Disiplini uygulamalarının çalışan performansı üzerinde pozitif ve istatistiki açıdan anlamlı etkiye sahip olduğu belirlenmiştir. Bu sonuçlar araştırma modelini destekleyici niteliktedir.

- İş Sağlığı ve Güvenliği uygulamaları, İş Disiplini ve çalışan performansının sektörler arasında farklılaşıp farklılaşmadığını belirlemek amacıyla yapılan analizlerde sektörler arasında bu değişkenlerin farklılık gösterdikleri görülmüştür. Buna göre bu değişkenlerin mamul sektöründe hizmet sektörüne oranla daha yüksek olduğu tespit edilmiştir.

\section{Öneriler}

- Araştırmada elde edilen temel sonuç İş Sağlığı ve Güvenliği uygulamaları ile İş Disiplini uygulamalarının çalışan performansını etkilediğidir. Bu nedenle firmaların iş Sağlığı ve Güvenliği noktasında ve İş Disiplini uygulamaları noktasında önlemler alması ve var olan uygulamalarını artırmaları gerekmektedir. Bu noktada İş Sağlığı ve Güvenliği eğitimleri vermek, İş Disiplini uygulamalarını kontrol ve revize etmek yerinde bir davranış olacaktır.

- Kurum içinde uygulanan iş Sağlığı ve Güvenliği uygulamalarının benimsetilmesi amacıyla ilgili kurum ve kuruluşlardan destek alınmalı ve bu uygulamaların çalışanlar için hayati derecede önemli olduğuna dair farkındalık düzeylerini arttıracak uyarı levhaları oluşturulmalıdır.

- Kurum kendi içinde İş Disiplini değişkenleri oluştururken çalışanların istek ve beklentilerini de göz önünde bulundurmalıdır.

- Çalışan performansını etkileyen diğer faktörlerin neler olabileceği konusunda araştırmalar yapılmalı ve performansı olumsuz yönde etkileyen faktörler elimine edilmelidir.

- $\mathrm{Bu}$ öneriler dişında son öneri ise bu konuda araştırma yapacak diğer araştırmacılara yöneliktir. Özellikle iş Sağlığı ve Güvenliği konusunda saha araştırmalarının yok denecek kadar az olması nedeniyle bu konuya daha fazla ağırlık verilip ve bu sonuçlar kurumlara bildirilmelidir.

\section{Kaynakça}

Ahmed, Y. M. (2016). Eğitimin çalışan performans1 üzerine etkileri (Hormuud Telecom, Somali) örneği.

Akpınar, T. (2014). İş Sağlı̆̆ı ve iş Güvenliği. Bursa: Ekin Yayınları. 
Balkır, Z. G. (2012). "İş Sağlığı ve Güvenliği hakkının korunması: işverenin iş Sağlığı ve Güvenliği organizasyonu." Sosyal Güvenlik Dergisi (SGD), 2(1): 56-91.

Ceylan, H. (2012). Türkiye'deki iş sağlığı ve güvenliği eğitimi sorunlar ve çözüm önerileri. Ejovoc (Electronic Journal of Vocational Colleges), 2(2), 94-104.

ÇASGEM (2013). Meslek hastalıkları, Akarsu, H. V., Ayan, B., Çakmak, E., Doğan, B., Eravcı, D., Karaman, E. ve Koçak, D. (Haz.), Ankara: Özyurt Matbaacılık.

Çopur, Z., Varli, B. E., Avşar, M., \& Şenbaş, M. (2006). Ege Üniversitesi Hastanesi'nde çalışan ev idaresi personelinin iş sağllğı ve güvenliği konusundaki görüşlerinin incelenmesi. Hacettepe Sağllk İdaresi Dergisi, 9(1), 39-53.

Demircioğlu, M. ve Centel, T. (2003). $\dot{I}_{S ̧} h u k u k u$. İstanbul: Beta Yayınları.

Diktaş, G. (2018). Örgütsel sinizm ve sosyal zekânın çalışan performansı ve işten ayrılma niyeti üzerindeki etkisi: İstanbul'daki reklam ajansı çalışanlarına yönelik bir araştırma (Master's thesis, Maltepe Üniversitesi, Sosyal Bilimler Enstitüsü).

Doğanay, A. (2014). Liderlik Tarzlarının Çalışanların Bağllık Seviyesi ve Performansına Etkisi: Başakşehir Belediyesinde Bir Uygulama. İstanbul Gelişim Üniversitesi Sosyal Bilimler Enstitüsü, İstanbul.

Gerek, N. (2009). İ̧s Sağllğg ve iş Güvenliği. Eskişehir: Anadolu Üniversitesi Yayınları.

Gümüştekin, G. E. ve Öztemiz, A. B. (2005). "Örgütlerde stresin verimlilik ve performansla etkileşimi.” Çukurova Üniversitesi Sosyal Bilimler Enstitüsü Dergisi, 14(1): 271-288.

Güzel, D. (2013). "Erzurum ilinde faaliyet gösteren bayan ve erkek kuaförlerinin, ergonomik çalışma koşulları, mesleki rahatsızlıklar ve iş memnuniyeti yönünden incelenmesi." Atatürk Üniversitesi Sosyal Bilimler Enstitüsü Dergisi, 17(3): 345-358.

Ivancevich, J. M. (2010). Human resource management (8 ed.). Boston: Irwin McGraw- Hill.

Karadoğan, E. (2014). Liman işçilerinin Sağll̆̆g ve Güvenliği. Ankara: Liman Iş Yayınları.

Kesen, M. (2015). Örgütsel demokrasinin çalışan performansı üzerine etkileri: örgütsel özdeşleşmenin aracılık rolü. Çankırı Karatekin Üniversitesi Sosyal Bilimler Enstitüsü Dergisi, 6(2), 535-562.

Kılıç, L. (2006). İsverenin iş Sağll̆ğ ve Güvenliğini sağlama hükümlülü̆̆̈̈ ve sorumluluğu. Ankara: Yetkin Yayınları.

Korkmazer, F., Ekingen, E., \& Yıldız, A. (2016). Psikolojik sermayenin çalışan performansına etkisi: Sağlık çalışanları üzerinde bir araştırma. Hacettepe Sağlık İdaresi Dergisi, 19(3), 271-281

Li, S., Xueqiu, H., \& Li, C. (2011). "Longitudinal relationship between economic development and occupational accidents in China." Accident Analysis \& Prevention, 43(1): 82-86.

Meydanlığlu, A. M. A. Sağlık Çalışanlarının Sağlığı ve Güvenliği. Balıkesir Sağlık Bilimleri Dergisi, 2(3), 192-199.

Pekdemir, I., Koçoğlu, M., \& Gürkan, G. (2014). Özerklik ve ödüllendirmenin çalışan performansı üzerindeki etkisinde çalışanın inovasyona yönelik davranışının aracılık rolüne yönelik bir araştırma. İstanbul Üniversitesi İsletme Fakültesi Dergisi, 43(2), 332-350.

Putri, D. O., Triatmanto, B., \& Setiyadi, S. (2018, April). "The effect of occupational health and safety, work environment and discipline on employee performance in a consumer goods company." In IOP Conference Series: Materials Science and Engineering, 337(1): 012036. IOP Publishing. 
Robinson J. and Elkan R. (1996) Health Needs Assessment. Pearson Professional Limited. New York.

Sekulová, K. \& Šimon, M. (2010). The Link Between Ergonomics And Occupational Diseases. Paper presented at the Proceedings of International Conference on Industrail and Information Engineering, France.

Solmaz, M., \& Solmaz, T. (2017). Hastanelerde iş sağlığı ve güvenliği. Gümüşhane Üniversitesi Sağllk Bilimleri Dergisi, 6(3), 147-156.

SSGK. (2018). Sosyal Sigortalar ve Genel Sağlık Sigortası Kanunu. Erişim Tarihi 05.06.2018, http://www.mevzuat.gov.tr/MevzuatMetin/1.5.5510.pdf

Sunar, F., \& Çınar, Ş. (2017). Hastane Çalışanlarının İş Sağlığı ve Güvenliği.

Tanrıverdi, H., Adıgüzel, O., \& Çiftçi, M. (2010). Sağlık yöneticilerine ati iletişim becerilerinin çalışan performansına etkileri; Kamu Hastanesi Örneği .Süleyman Demirel Üniversitesi Sosyal Bilimler Enstitüsü Dergisi, (11), 101-122.

TDK. (2018). Disiplin Kavramı Erişim Tarihi 06.07.2018, http://www.tdk.gov.tr/index.php?option=com_bts\&arama=kelime\&guid=TDK.GTS.5b3f78db $\underline{3 \mathrm{db} 172.50741263}$

TMMOB (2010). İs Sa ğllğl ve Güvenliği oda raporu. Ankara: Türkiye Makine Mühendisleri Odas1 Birliği.

Turan, Ö. (2016). Ofis çalışmalarında ergonomik risklerin iş Să̆llğı ve Güvenliği açısından değerlendirilmesi. Yayımlanmamış yüksek lisans tezi, İstanbul Aydın Üniversitesi Fen Bilimleri Enstitüsü, İstanbul.

Tüzüner, V. L., \& Özaslan, B. Ö. (2011). Hastanelerde iş sağlığı ve güvenliği uygulamalarının değerlendirilmesine yönelik bir araştırma. Istanbul University Journal of the School of Business Administration, 40(2), 138-154.

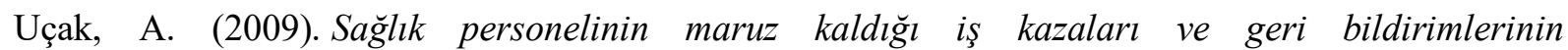
değerlendirilmesi (Master's thesis, Afyon Kocatepe Üniversitesi, Sağlık Bilimleri Enstitüsü).

Uyargil, C., Adal, Z., Ataay, İ. D., Acar, A .C., Özçelik, O., Dündar, G. ve Tüzüner, L. (2009). İnsan kaynakları yönetimi. İstanbul: Beta Yayınları.

W.W. Daniel - Neil Millward (1983), Workplace Industrial Relations in Britain, London: Heinemann Educational Books.

Yiğit, A. (2011). Işs Güvenliği. Bursa: Alfa Akademi. 